\title{
The clinical course of patients with adrenal incidentaloma: is it time to reconsider the current recommendations?
}

\author{
Darko Kastelan $^{1,2}$, Ivana Kraljevic ${ }^{1}$, Tina Dusek ${ }^{1,2}$, Nikola Knezevic ${ }^{3}$, Mirsala Solak ${ }^{1}$, \\ Bojana Gardijan ${ }^{4}$, Marko Kralik ${ }^{5}$, Tamara Poljicanin ${ }^{6}$, Tanja Skoric-Polovina ${ }^{1}$ and \\ Zeljko Kastelan ${ }^{2,3}$ \\ ${ }^{1}$ Department of Endocrinology, University Hospital Centre Zagreb, Kispaticeva 12, 10000 Zagreb, Croatia, \\ ${ }^{2}$ School of Medicine, University of Zagreb, Salata 3, 10000 Zagreb, Croatia, ${ }^{3}$ Department of Urology, \\ University Hospital Centre Zagreb, Kispaticeva 12, 10000 Zagreb, Croatia, ${ }^{4}$ Department of Internal Medicine, \\ University Hospital Merkur, Zajceva 19, 10000 Zagreb, Croatia, ${ }^{5}$ Department of Radiology, University Hospital \\ Centre Zagreb, Kispaticeva 12, 10000 Zagreb, Croatia and ${ }^{6}$ Croatian Institute of Public Health, \\ Rockefellerova 7, 10000 Zagreb, Croatia
}

Correspondence should be addressed to D Kastelan Email darko.kastelan@ kbc-zagreb.hr

\begin{abstract}
Objective: The current guidelines for the management of adrenal incidentaloma advise hormonal and radiological follow-up of patients for 2-5 years after the initial diagnosis. However, the vast majority of adrenal incidentaloma are non-functional benign cortical adenomas that require no treatment, so the routine application of the current strategies often results in a number of unnecessary biochemical and radiological investigations. The aim of this study was to analyse the clinical course of patients with adrenal incidentaloma and to provide a critical review of the current management strategy of the disease.

Design and methods: This was a retrospective study performed in the Croatian Referral Center for adrenal gland disorders. The study included 319 consecutive patients with adrenal incidentaloma, 174 of which were followed for at least 24 months. Results: The vast majority of patients were diagnosed with benign adrenal masses, whereas in about $5 \%$ of them adrenal tumor corresponded to adrenal carcinoma or metastasis. Tumor density was found to be superior to tumor size in distinguishing benign adrenal masses from malignant tumors and pheochromocytomas. During the follow-up, no patient demonstrated a clinically significant increase in tumor size. In addition, no changes, either in metanephrines and normetanephrines or in the activity of renin-aldosterone axis, were observed during the follow-up. Six patients developed subclinical Cushing's syndrome (SCS) whereas eight patients with SCS showed biochemical remission during follow-up. Conclusion: The study suggests that the risk of an adrenal mass initially diagnosed as benign and non-functional becoming malignant or hormonally active is extremely low. Therefore, the clinical management of those patients should be tailored on an individual basis in order to avoid unnecessary procedures.
\end{abstract}

\section{Introduction}

The term 'adrenal incidentaloma' covers a wide range of adrenal pathologies unexpectedly found during work-up performed for an indication unrelated to suspected adrenal disease. The prevalence of such incidentally discovered adrenal masses increases with age and is reported in more than $7 \%$ of patients aged over 70 (1). The major clinical
(C) 2015 European Society of Endocrinology Printed in Great Britain concern in adrenal incidentaloma is the risk of malignancy and hormone overproduction, but the vast majority of adrenal masses are non-functional benign cortical adenomas that require no treatment $(2,3,4,5,6)$.

Given the relatively low prevalence of functional and malignant lesions, diagnostic tests for adrenal

Published by Bioscientifica Ltd. 
incidentaloma need to have high sensitivity and specificity in order to capture all the clinically important adrenal lesions and to avoid a high rate of false positive results. Guidelines for the management of adrenal incidentalomas suggest multiple repetitions of radiological and biochemical tests. Patients who are not candidates for surgery should undergo re-imaging 3-6 months after the initial diagnosis and then annually for the next 1-2 years. Furthermore, annual biochemical follow-up is advised for up to 4-5 years after the establishment of the diagnosis $(3,7,8)$. However, given the low probability of the transformation of a benign and non-functional adrenal mass to a malignant or functional one (2), the routine application of the current strategies is likely to result in a number of unnecessary biochemical and radiological investigations. Such an approach is costly and it does not take into account harmful consequences of diagnostic evaluation such as patients' anxiety associated with repeated clinical visits and a high rate of false positive results leading to further testing or unnecessary adrenalectomy. Moreover, radiation exposure associated with repeated CT imaging increases the risk of fatal cancer (2).

The described problems appear to call for the reconsideration of the current practices in the management of adrenal incidentalomas. Therefore, in the present study we analysed the clinical course of patients with adrenal incidentaloma. Based on our results and on the results from existing literature, we provide a critical review of the current follow-up strategy for adrenal incidentaloma. We suggest its reconsideration in order to avoid unnecessary, costly and sometimes harmful diagnostic work-up.

\section{Subjects and methods}

\section{Patients}

The study population comprised 319 consecutive patients (111 males, 208 females: median age 58 (25-86) years) who were referred to the Department of Endocrinology, University Hospital Zagreb, between January 2008 and June 2013.

In all the study subjects, adrenal tumor was diagnosed by the unenhanced CT. Adrenal tumors characterised by the attenuation value of $\leq 10$ Hounsfield units (HU) were considered as benign adrenocortical adenomas. The clinical indication for the CT image that led to the diagnosis of adrenal mass included acute abdominal pain (21.3\%), various gastrointestinal tract disorders $(20.4 \%)$, renal colic and other urinary tract disorders $(26.9 \%)$, abdominal infection (6.3\%), pulmonary diseases $(3.4 \%)$ and a group of other less frequent indications, which accounted for $11.0 \%$ of the cases. In $10.7 \%$ of the patients, adrenal incidentaloma was discovered by abdominal ultrasound during a regular check-up, and then it was confirmed by CT. Patients with a history of a malignant disease within 10 years before entering the study were excluded from the analysis. The study was approved by the Local Ethics Committee.

\section{Hormone assays}

All the laboratory analyses were performed using standard assays. Serum cortisol, free urinary cortisol, plasma adrenocorticotropin (ACTH) and DHEAs were measured with electrochemiluminescence immunoassay (Roche). HPLC (Chromsystems, Munich, Germany) was used for the measurement of urinary metanephrine and normetanephrine. Plasma renin activity and aldosterone were assessed in hypertensive patients using RIA kits (Sorin Biomedica, Saluggia, Italy). Androstendione and 17-OHP were measured by ELISA (DRG, Marburg, Germany), whereas testosterone was determined by chemiluminescent immunoassay using the VITROS ECi immunodiagnostic system (Ortho Clinical Diagnostics, Rochester, NY, USA). Hormone reference values were provided by the manufacturer.

\section{Imaging studies}

In the study, all the CT data were evaluated by a single radiologist $(\mathrm{M} \mathrm{K})$. Initial $\mathrm{CT}$ scanning was done on different scanners available in various medical institutions in Croatia, including ours. However, in all the patients at least one CT scan was performed at the Department of Radiology, University Hospital Centre Zagreb, using the Somatom Sensation 40 (Siemens, Erlangen, Germany) and LightSpeed Ultra 8 (GE Healthcare, Little Chalfont, UK) CT scanners with a slice thickness of $1.5 \mathrm{~mm}$ or $2 \mathrm{~mm}$.

\section{Study protocol}

During the study period, a total of 319 patients diagnosed with adrenal incidentaloma were included in the baseline analysis. The data of 174 patients were available for the final analysis, which was done 24 months after entering the study. The patient flowchart is presented in Fig. 1.

Subclinical Cushing's syndrome (SCS) was defined by the presence of plasma cortisol level $>83 \mathrm{nmol} / \mathrm{l}$ after $1 \mathrm{mg}$ overnight dexamethasone suppression plus either elevated urinary cortisol $(>379 \mathrm{nmol} / 24 \mathrm{~h})$ or low 


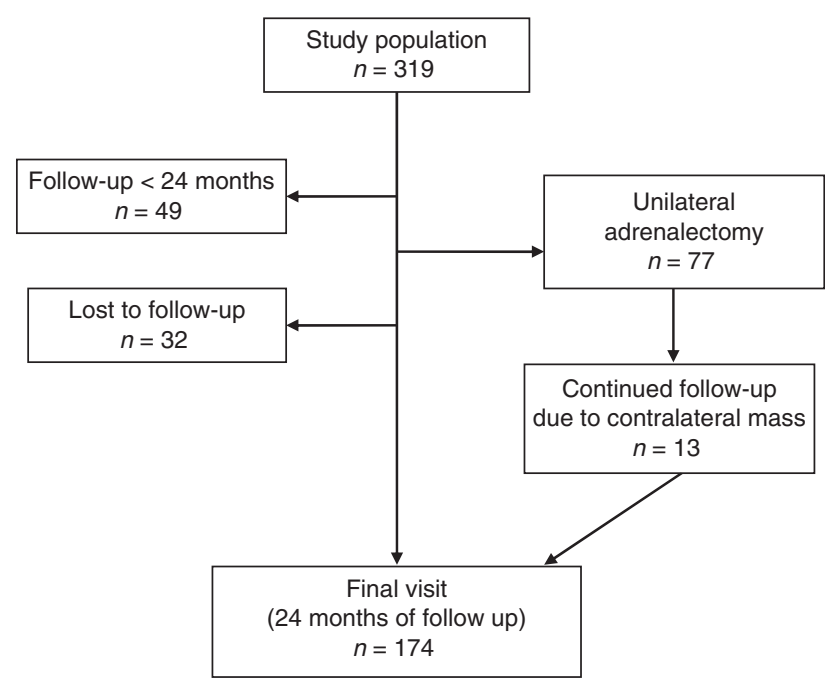

Figure 1

Patient flowchart.

ACTH $(<2.2 \mathrm{pmol} / \mathrm{l})$. All the patients were evaluated for the presence of hypertension, dyslipidemia, osteoporosis and diabetes mellitus/impaired glucose tolerance. Hypertension was defined as the use of anti-hypertensive drugs or blood pressure $>140 / 90 \mathrm{mmHg}$. Dyslipidemia was defined as the use of anti-lipemic drugs or abnormal levels of cholesterol $(>6.5 \mathrm{mmol} / \mathrm{l})$ and tryglicerides ( $>1.69 \mathrm{mmol} / \mathrm{l})$. Osteoporosis was defined as bone mineral density $T$-score $\leq-2.5$ on lumbar spine, femoral neck or total hip. Diabetes was defined as fasting plasma glucose $\geq 7 \mathrm{mmol} / \mathrm{l}$ or as plasma glucose $>11.1 \mathrm{mmol} / \mathrm{l}$ $2 \mathrm{~h}$ after a 75-g oral glucose load. Impaired glucose tolerance was defined as fasting plasma glucose between 5.6 and $6.9 \mathrm{mmol} / 1$ or as plasma glucose between 7.8 and $11.1 \mathrm{mmol} / \mathrm{l} 2 \mathrm{~h}$ after a 75 -g oral glucose load.

According to the Croatian guidelines for the management of patients with adrenal incidentaloma (9), surgery was considered in the patients with functional tumors or masses larger than $4 \mathrm{~cm}$ or masses exhibiting imaging characteristics suspected of malignancy. In the case of the SCS, a unilateral laparoscopic adrenalectomy was performed in all the patients younger than 50 years of age, as well as in those over 50 with comorbidities that could be attributed to cortisol excess. No surgery was required in the other patients, and in their case biochemical work-up and unenhanced CT were repeated 6 and 24 months after the initial diagnosis. Adrenal lesions that did not show an increase in size $>10 \mathrm{~mm}$ during 24 months of the followup were considered benign. Eleven patients with adrenal masses larger than $4 \mathrm{~cm}$ (median $45 \mathrm{~mm}$, range $40-55 \mathrm{~mm}$ ) but with otherwise benign CT phenotype refused surgery and were included in the follow-up group.

\section{Statistical analysis}

Statistical analysis was performed using SPSS 14.0 (SPSS). A $P<0.05$ was considered to be significant. For simultaneous testing, an adjustment of $P$ values using Bonferroni correction was performed. The normality of the distributions was tested using the Kolmogorov-Smirnov test. The data were expressed as the median and range. For the comparison between the groups of data, the MannWhitney test was used for the numerical variables and the $\chi^{2}$ test for the categorical ones. The analysis of the repeated samples was done by the Wilcoxon and Friedman tests. MedCalc version 2.0 was used for the analysis of specificity and sensitivity, as well as for the calculation of 95\% CI (www.medcalc.org/calc/diagnostic_test.php).

\section{Results}

Among the 319 patients examined, 248 had unilateral adrenal masses, and both glands were affected in 71 patients. The median size of the tumors was 25 (10-176) $\mathrm{mm}$. Overall, 221 (69.3\%) patients had hypertension, 89 (27.9\%) had glucose intolerance or type 2 diabetes, 141 (44.2\%) had dyslipidemia and 20 (6.3\%) had osteoporosis.

In 238 (74.6\%) patients, the clinical diagnosis was a benign non-functional tumor, 17 (5.3\%) patients had pheochromocytoma, 11 (3.4\%) had adrenocortical carcinoma, 3 (1\%) patients had adrenal metastases whereas one patient had extragastrointestinal stromal tumor. Forty-nine (15.4\%) patients were diagnosed with benign functional tumors, 36 of which had SCS, 12 had primary hyperaldosteronism and one patient had an excess of androgens (Table 1).

Of the 77 patients (24.1\%) who underwent unilateral adrenalectomy, 37 had adrenal adenoma or hyperplasia, 11 had adrenocortical carcinoma, 17 had pheochromocytoma, three were diagnosed with hemangioma, three with myelolipoma, three with adrenal metastasis, two patients had cysts of the adrenal gland and one patient had extragastrointestinal stromal cell tumor.

\section{CT characteristics of adrenal tumors}

Tumor density was evaluated in 310 patients with 379 adrenal masses, whereas for nine patients no tumor attenuation values were reported by the radiologist. In 291 cases of adrenal mass the attenuation value on unenhanced CT was $\leq 10 \mathrm{HU}$, whereas in 92 of them it was $>10 \mathrm{HU}$. The 
Table 1 Clinical diagnosis in patients with adrenal incidentaloma.

\begin{tabular}{|c|c|c|c|c|}
\hline Diagnosis & & & No. & $\begin{array}{c}\text { Size median } \\
\text { (range) }\end{array}$ \\
\hline $\begin{array}{l}\text { Non-functional } \\
\text { adenoma }\end{array}$ & & & $231(72.4 \%)$ & $25.5(10-61)$ \\
\hline Functional adenoma & & & $46(14.4 \%)$ & \\
\hline SCS & & 33 & & $40(10-72)$ \\
\hline PHA & & 12 & & $19(10-42)$ \\
\hline Androgens & & 1 & & - \\
\hline Other benign masses & & & $10(3.1 \%)$ & - \\
\hline Myelolipoma & & 3 & & \\
\hline $\begin{array}{l}\text { SCS } \\
\text { Hemanginma }\end{array}$ & 1 & 3 & & \\
\hline $\begin{array}{l}\text { Hemangioma } \\
\text { SCS }\end{array}$ & 2 & 3 & & \\
\hline Cyst & & 3 & & \\
\hline Lipoma & & 1 & & \\
\hline Pheochromocytoma & & & $17(5.3 \%)$ & $55(16-90)$ \\
\hline Carcinoma & & & $11(3.5 \%)$ & $75(45-176)$ \\
\hline Functional & & 5 & & \\
\hline Non-functional & & 6 & & \\
\hline $\begin{array}{l}\text { Other malignant } \\
\text { masses }\end{array}$ & & & $4(1.3 \%)$ & $68.5(49-110)$ \\
\hline Metastases & & 3 & & \\
\hline EGIST & & 1 & & \\
\hline
\end{tabular}

SCS, subclinical Cushing's syndrome; EGIST, extragastrointestinal stromal tumor; PHA, primary hyperaldosteronism.

attenuation value of $>10 \mathrm{HU}$ was associated with a larger tumor size (32 (10-176) vs $24(10-120) \mathrm{mm} ; P<0.001)$. In addition, the patients with attenuation values of $>10 \mathrm{HU}$ were more likely to undergo adrenalectomy (55.0 vs $12.7 \%$; $P<0.001)$ and were more likely to have a functional tumor (40.3 vs $17.2 \% ; P<0.001$ ).

The tumor attenuation value was $>10 \mathrm{HU}$ in all the patients with adrenocortical carcinoma, adrenal metastasis or pheochromocytoma. The ROC curve analysis, which involved only those patients with confirmed adrenal histology, showed that the specificity of the adrenal tumor attenuation value of $\leq 10 \mathrm{HU}$ to rule out malignant adrenal mass or pheochromocytoma was $100 \%$, with the sensitivity of $65 \%$ (positive predictive value $100 \%$, negative predictive value $67 \%, \mathrm{AUC}=0.924, P=0.03, \mathrm{CI}$ 0.863-0.986; Fig. 2). With regard to tumor size, adrenal masses in patients with adrenocortical carcinoma, metastasis and pheochromocytoma were significantly larger compared to those with benign lesions (Table 1). The cutoff of $\leq 4 \mathrm{~cm}$ had $91 \%$ specificity and $31 \%$ sensitivity (positive predictive value $82 \%$, negative predictive value $48 \%, \mathrm{AUC}=0.736, P=0.05$, CI 0.605-0.859; Fig. 2) to rule out malignant tumor or pheochromocytoma.

As for the hormonally active adrenal masses, the size of the tumor was significantly lower in patients with primary hyperaldosteronism compared to those with SCS or pheochromocytoma with the values of 19 (10-42), $40(10-72)$ and $55(16-90) \mathrm{mm}(P<0.001)$ respectively.

\section{Subclinical Cushing's syndrome}

Table 2 compares the demographic and clinical characteristics of patients with SCS as opposed to those with non-functional adenomas. Thirty-six patients had hormonal characteristics of SCS, which was found to be more common among those with bilateral adrenal tumors (21.1 vs $8.4 \% ; P<0.001$ ). All of the patients with SCS had cortisol levels $>83 \mathrm{nmol} / \mathrm{l}$ in overnight $1 \mathrm{mg}$ dexamethasone test; 34 (94.4\%) had ACTH levels <2.2 pmol/l, whereas 9 (25\%) patients had elevated urinary free cortisol. Overall, 26 (72.2\%) patients with SCS had hypertension, $12(33.3 \%)$ had glucose intolerance or type 2 diabetes, 16 (44.4\%) had dyslipidemia, and 3 $(8.3 \%)$ had osteoporosis. No differences were established between the patients with SCS and those with nonfunctional adenomas with regard to the BMI and waist circumference, or to the frequency of hypertension, type 2 diabetes, dyslipidemia or osteoporosis. However, patients with SCS had larger tumors compared to those with non-functional adenomas $(44(17-72)$ vs 25.5 (10-61) $\mathrm{mm} ; P<0.001)$.

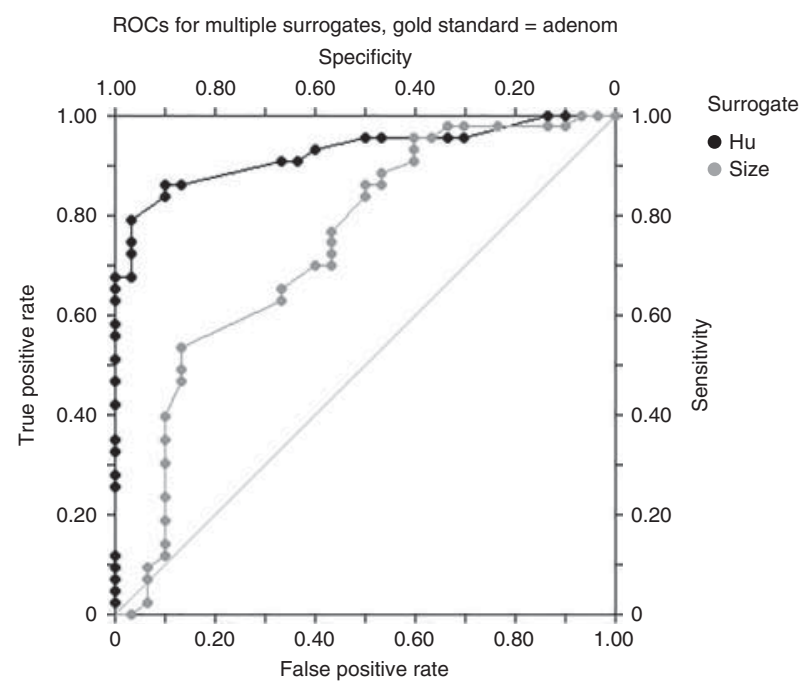

Figure 2

Value of the tumor size and tumor density for distinguishing benign adrenal masses from malignant tumors and pheochromocytomas. 
Table 2 Clinical characteristics of patients with SCS and nonfunctional adenomas. Data are presented as median (range) or percentage.

\begin{tabular}{|c|c|c|c|}
\hline Variable & SCS $(n=36)$ & NFA $(n=231)$ & $\boldsymbol{P}$ \\
\hline Age & $57(38-76)$ & $59(32-86)$ & 0.245 \\
\hline Gender (F/M) & $27 / 9$ & $124 / 73$ & 0.671 \\
\hline Tumor size & $44(17-72)$ & $25.5(10-61)$ & $<0.001$ \\
\hline Weight & $79.7(45-169.5)$ & $80(44-130)$ & 0.382 \\
\hline $\mathrm{BMI}$ & $31.5(18-56)$ & $29.1(17-46.5)$ & 0.089 \\
\hline Waist & 106 (87-119) & $99(78-129)$ & 0.251 \\
\hline HOMA index & $2.1(0.7-9.4)$ & $1.7(0.4-30.3)$ & 0.770 \\
\hline Hypertension & $26(72.2 \%)$ & $132(57.1 \%)$ & 0.538 \\
\hline Osteoporosis & $3(8.3 \%)$ & $28(12.1 \%)$ & 0.509 \\
\hline Dyslipidemia & $16(44.4 \%)$ & $103(44.5 \%)$ & 0.987 \\
\hline \multirow{2}{*}{$\begin{array}{l}\text { Diabetes/glucose } \\
\text { intolerance }\end{array}$} & & & 0.092 \\
\hline & $12(33.3 \%)$ & $31(13.4 \%)$ & \\
\hline
\end{tabular}

NFA, non-functional adenoma; SCS, subclinical Cushing's syndrome; HOMA, homeostasis model assessment.

Twenty-two patients with SCS underwent unilateral adrenalectomy. Patients with SCS who underwent surgical resection of the tumor had a larger tumor size $(P<0.001)$ and tended to have more hypertension $(P=0.02)$ compared to those who did not need surgery. No difference in the prevalence of diabetes, osteoporosis and dyslipidaemia were found between the two groups of patients (Table 3). Biochemical work-up performed 6 months after the surgery showed significantly lower 1-mg dexamethasone cortisol concentrations (39 vs $137.5 \mathrm{nmol} / \mathrm{l} ; P<0.01$ ), lower urinary free cortisol levels (178 vs $311.5 \mathrm{nmol} / \mathrm{dU} ; P=0.01)$ and higher ACTH concentrations ( 1.55 vs $0.8 \mathrm{pmol} / \mathrm{l} ; P=0.03$ ). Postoperatively, patients with SCS had a lower body weight (81.5 $(45-128)$ vs $86.7(45-135) \mathrm{kg} ; P=0.01)$ and a lower BMI (31.1 (18-53.3) vs $\left.33.4(18-56) \mathrm{kg} / \mathrm{m}^{2} ; P=0.02\right)$ than before the operation. No differences were found in the blood glucose level and lipid profile, whereas in 15 out of 22 patients the remission of the disease was associated with improved blood pressure, including cured hypertension in four patients $(P=0.006)$.

\section{Follow-up study}

In 174 patients the radiological and biochemical tests were repeated 6 and 24 months after the initial diagnosis. In $7(4.0 \%)$ patients, a tumor size increase of $>5 \mathrm{~mm}$ was noticed, whereas in one patient the mass size increase was $>10 \mathrm{~mm}$ (from 25 to $36 \mathrm{~mm}$ ). No further mass increase was observed during the extended follow-up of 4 years, so none of the patients needed surgery due to mass enlargement. Moreover, a tumor size decrease of $>10 \mathrm{~mm}$ was found in $12(6.9 \%)$ patients.

With regard to tumor function, no changes either in metanephrines and normetanephrines or in the activity of renin-aldosterone axis were observed during the followup. Five patients developed SCS but without any clinical relevance. Hence, these patients did not undergo surgery. On the other hand, one patient developed SCS together with metabolic worsening and was considered for surgery. In that patient, the change of the hormonal profile was not associated with a tumor size increase. None of the patients developed overt Cushing's syndrome during the follow-up period. Eight of the 14 patients with baseline SCS showed improvement of the hormonal profile and did not fulfil the criteria for SCS on the final visit.

\section{Discussion}

The widespread use of imaging techniques results in the frequent detection of adrenal tumors among the general population. Although in most cases adrenal masses are benign, they represent an important clinical concern due to the risk of malignancy and possible hormonal hyperfunction. The present study involved 319 patients with adrenal masses, $74.6 \%$ of which turned out to be benign nonfunctional tumors. In the study group, nearly $5 \%$ of the patients were diagnosed with adrenal carcinoma or adrenal metastasis from extraadrenal tissues, whereas another $5 \%$ of the patients had pheochromocytoma. Our findings are in line with the data of the previous studies that reported on the etiology of adrenal incidentalomas $(10,11)$.

SCS was the most common functional tumor in our cohort and was found in $11.3 \%$ patients with adrenal incidentaloma. It is interesting that two patients with SCS

Table 3 Clinical characteristics of patients with SCS in relation to treatment option. Data are presented as median (range) or percentage.

\begin{tabular}{|c|c|c|c|}
\hline Variable & $\begin{array}{c}\text { Adrenalectomy } \\
(n=22)\end{array}$ & $\begin{array}{c}\text { Conservative } \\
(n=14)\end{array}$ & $\boldsymbol{P}$ \\
\hline Age & $57.5(43-71)$ & $57.0(41-76)$ & 0.877 \\
\hline BMI & $33.4(18-56)$ & $29.5(20-51)$ & 0.146 \\
\hline Size & $54(27-72)$ & $32(24-45)$ & $<0.001$ \\
\hline $\begin{array}{c}\text { Diabetes/glucose } \\
\text { intolerance }\end{array}$ & $8(36.4 \%)$ & $4(28.6 \%)$ & 0.146 \\
\hline Hypertension & $19(86.3 \%)$ & $7(50 \%)$ & $0.020^{a}$ \\
\hline Osteoporosis & $3(13.6 \%)$ & 0 & 0.207 \\
\hline Dyslipidemia & $9(40.9 \%)$ & $7(50 \%)$ & 0.577 \\
\hline
\end{tabular}

SCS, subclinical Cushing's syndrome.

${ }^{a}$ Not significant after Bonferroni correction. 
had histological diagnosis of hemangioma and one patient had myelolipoma. Since those two types of tumors are usually considered to be non-functional, hormonal findings consistent with subtle cortisol excess might be attributed to false positive test results, which is not uncommon in patients with adrenal incidentaloma being screened for SCS. However, patients with functional adrenal hemangioma and myelolipoma have already been reported in the literature $(12,13)$, which may have also been the case in our study.

The prevalence of SCS in the literature ranges from 5 to $30 \%$ depending mainly on diagnostic criteria used in different studies. Since there is no gold standard for the diagnosis of SCS, most authors use a combination of tests $(1,4,7,10,14,15)$. We used $1 \mathrm{mg}$ overnight dexamethasone test as a screening test for SCS. The cut-off for an abnormal cortisol response was set at $83 \mathrm{nmol} / \mathrm{l}$ as it seems to be the best compromise between sensitivity and specificity of the test (15). In the patients with positive overnight dexamethasone test, the diagnosis of SCS was confirmed by either elevated urinary free cortisol or low ACTH.

A diagnostic work-up in patients with adrenal tumors is conducted with the aim to distinguish between benign and malignant tumors, as well as between functional and non-functional masses. A number of studies have shown that the unenhanced CT attenuation value is the most reliable tool in the differentiation of benign and malignant lesions $(7,16)$. Adrenocortical adenomas are usually rich in lipids and show low attenuation values, whereas high-density masses are suspected for malignancy. On the other hand, about $30 \%$ of cortical adenomas have low lipid content and exhibit high attenuation values. Nevertheless, it has been reported that mass density of $\leq 10 \mathrm{HU}$ had the best combined sensitivity and specificity to differentiate benign from malignant tumors $(7,16,17)$.

Pheochromocytomas are also characterized by high density on unenhanced CT, although there were a few anecdotal reports of lipid-rich (i.e., low-density) pheochromocytomas $(18,19)$. At least in some of the cases this could be a diagnostic pitfall, as necrotic areas, which are common in pheochromocytoma, have been accounted for low density. In the present study, none of the patients with a low HU mass had elevated urinary metanephrines or normetanephrines, as hallmarks of pheochromocytoma. This is in accordance with the data published by Sane et al. (20) reporting the same finding in the series of 174 patients with adrenal incidentalomas. Therefore, it appears that patients with homogenous, low-density adrenal masses may not need to be screened for pheochromocytoma.

In line with the observed data on the relationship between tumor density and tumor nature, the ROC curve analysis demonstrated that the cut-off value of $\leq 10 \mathrm{HU}$ had $100 \%$ specificity to rule out adrenal carcinoma, adrenal metastases and pheochromocytoma. The sensitivity, positive predictive value and negative predictive value were 65,100 and $67 \%$ respectively. Moreover, tumor density was shown to be superior to tumor size in differentiating adrenal adenomas from non-adenomas (Fig. 2). Similar results were obtained in the study published by Hamrahian et al. (16).

As the natural history of adrenal incidentalomas is largely unknown, the follow-up strategy for this disease is open to much discussion in literature. The risk of an adrenal incidentaloma that has initially been considered benign to become malignant is very low (2). Similarly, it is unlikely that a non-functional adrenal mass evolves to a functional one. However, most of the recent guidelines recommend hormonal and radiological follow-up in 6-12 months intervals for $2-5$ years $(7,8,21,22)$ after the initial diagnosis. Such an approach suffers from low specificity and is associated with a high rate of false positive results, leading to the emotional burden for patients and a significant financial cost (2). Moreover, exposure to ionising radiation from repeated CT scans increases the future cancer risk to the level that is similar to the risk of the adrenal lesion becoming malignant (2). Therefore, the follow-up strategy for the patients with adrenal incidentaloma should be tailored carefully and based on clinical judgement.

Our series consisted of 319 patients with adrenal incidentalomas, 174 of which were followed for at least 24 months. We observed an increase in tumor size of more than $1 \mathrm{~cm}$ (from 25 to $36 \mathrm{~mm}$ ) in only one patient. The tumor had a benign radiological phenotype (attenuation value $\leq 10 \mathrm{HU}$ ) and did not increase in size during the follow-up for the next 4 years, so the patient was not considered for surgery. Interestingly, a decrease in tumor size of more than $10 \mathrm{~mm}$ was noticed in as many as 12 patients.

As has previously been reported, SCS is the most common functional abnormality among patients with adrenal incidentalomas $(10,23)$, which was also found in $11.3 \%$ of our study population. Several observational studies reported that subtle cortisol excess in SCS is associated with increased cardiovascular risk $(24,25)$. However, the data on the clinical benefit of surgical treatment in patients with SCS are fairly inconsistent $(26,27,28)$. In our study, we observed 
no difference in the prevalence of diabetes, hypertension or dyslipidaemia in the patients with SCS compared to those with non-functional adenoma. On the other hand, compared to the preoperative values, the patients with SCS experienced an improvement of hypertension, as well as a significant decrease of body weight and BMI after the adrenal surgery. Although our findings suggest that patients with SCS might, in some aspects, benefit from adrenalectomy, the retrospective and non-randomised design of our study limits us in drawing definitive conclusions. Moreover, decreased body weight and blood pressure-lowering effects might be attributed to the surgery per se, regardless of the hormonal status. Therefore, in the absence of a proper control group, the effects of the surgery on weight loss and on the improvement of hypertension cannot be separated from the effects of the resolution of SCS on those parameters.

Due to the risk of adrenal tumor becoming functional over time, the current recommendations suggest that patients with adrenal incidentaloma should be followed biochemically for up to 5 years $(7,8,21,22)$. A most recent follow-up study of adrenal incidentaloma demonstrated that $8.2 \%$ of patients developed SCS during the 5 years of the follow-up, with the risk being particularly increased in patients with larger adenoma size (29). In contrast, our data showed that the risk of the development of clinically relevant functional lesion is low. The reason for the discrepant results is not clear, as both studies used the same criteria for the diagnosis of SCS and the patients had similar demographic characteristics. Therefore, further prospective studies are needed to obtain a definite conclusion on that issue. In our cohort, only six of 160 patients initially diagnosed with a non-functional adrenal tumor developed SCS during the follow-up period; in five of them this occurred without any clinical correlates. Those patients were followed for 4 years and no clinical worsening or progression to overt Cushing's syndrome was noticed. None of the patients developed pheochromocytoma or primary hyperaldosteronism during the follow-up either.

We believe that the major limitation of our study is its retrospective nature. On the other hand, all the patients were managed in the single center using a standardized protocol, which in our opinion is the main strength of the study. Moreover, the patients were followed for a minimum of 2 years, or at least 4 years if hormonal or radiological changes were observed. The high proportion of the patients who did not complete the 24 months of the follow-up represents another important limitation of the study. However, the baseline data of these patients did not differ in demographic data, imaging or hormonal characteristics from those who completed the follow-up period. Finally, our study excluded patients with a history of cancer in the preceding 10 years, so our results do not necessarily apply to those with a more recent cancer history.

In conclusion, the present study demonstrated that the risk of an adrenal mass initially diagnosed as benign and non-functional becoming malignant or hormonally active is rather low. In addition, the results of the study suggest that the diagnostic approach should be tailored on an individual basis in order to avoid unnecessary procedures. In adrenal masses with the attenuation value of $<10 \mathrm{HU}$, routine screening for pheochromocytoma may not be required. There may be no need either to repeat testings for primary aldosteronism during the follow-up, whereas a long-term evaluation for subtle cortisol hypersecretion may only be needed in patients whose cardiovascular risk profile has worsened. Finally, it is questionable whether there is a need for radiological follow-up of low-density cortical masses.

\section{Declaration of interest}

The authors declare that there is no conflict of interest that could be perceived as prejudicing the impartiality of the research reported.

\section{Funding}

The study was supported by Research Program No. 108-0000000-3496 of the Croatian Ministry of Science, Education and Sport.

\section{Acknowledgements}

We also thank Tamara Sladoljev Agejev for her help in the preparation of the manuscript.

\section{References}

1 Kloos RT, Gross MD, Francis IR, Korobkin M \& Shapiro B. Incidentally discovered adrenal masses. Endocrine Reviews 199516 460-484. (doi:10.1210/edrv-16-4-460)

2 Cawood TJ, Hunt PJ, O’Shea D, Cole D \& Soule S. Recommended evaluation of adrenal incidentalomas is costly, has high false-positive rates and confers a risk of fatal cancer that is similar to the risk of the adrenal lesion becoming malignant; time for a rethink? European Journal of Endocrinology/European Federation of Endocrine Societies 2009 161 513-527. (doi:10.1530/EJE-09-0234)

3 Zeiger MA, Siegelman SS \& Hamrahian AH. Medical and surgical evaluation and treatment of adrenal incidentalomas. Journal of Clinical Endocrinology and Metabolism 201196 2004-2015. (doi:10.1210/jc. 2011-0085)

4 Young WF Jr. Management approaches to adrenal incidentalomas. A view from Rochester, Minnesota. Endocrinology and Metabolism Clinics of North America 200029 159-185. (doi:10.1016/S0889-8529(05)70122-5)

5 Young WF Jr. Clinical practice. The incidentally discovered adrenal mass. New England Journal of Medicine 2007356 601-610. (doi:10.1056/ NEJMcp065470) 
6 Kasperlik-Załuska AA, Otto M, Cichocki A, Rosłonowska E, Słowińska-Srzednicka J, Jeske W, Papierska L \& Zgliczyński W. Incidentally discovered adrenal tumors: a lesson from observation of 1,444 patients. Hormone and Metabolic Research 200840 338-341. (doi:10.1055/s-2008-1073167)

7 Terzolo M, Stigliano A, Chiodini I, Loli P, Furlani L, Arnaldi G, Reimondo G, Pia A, Toscano V, Zini M et al. AME position statement on adrenal incidentaloma. European Journal of Endocrinology/ European Federation of Endocrine Societies 2011164 851-870. (doi:10.1530/EJE-10-1147)

8 Zeiger MA, Thompson GB, Duh QY, Hamrahian AH, Angelos P, Elaraj D, Fishman E, Kharlip J, American Association of Clinical Endocrinologists \& American Association of Endocrine Surgeons . The American Association of Clinical Endocrinologists and American Association of Endocrine Surgeons medical guidelines for the management of adrenal incidentalomas. Endocrine Practice 200915 1-20. (doi:10.4158/EP.15.S1.1)

9 Kastelan D, Dusek T, Aganović I, Stern-Padovan R, Kuzmanić D, Kastelan Z, Knezevic N, Crncevic-Orlic Z, Kraljevic I, Dzubur F et al. Management of adrenal incidentaloma: the position statement of the Croatian referral center for adrenal gland disorders. Lijeĉniçki Vjesnik 2010132 71-75.

10 Mantero F, Terzolo M, Arnaldi G, Osella G, Masini AM, Alì A, Giovagnetti M, Opocher G \& Angeli A. A survey on adrenal incidentaloma in Italy. Study Group on Adrenal Tumors of the Italian Society of Endocrinology. Journal of Clinical Endocrinology and Metabolism 200085 637-644. (doi:10.1210/jcem.85.2.6372)

11 Barzon L, Sonino N, Fallo F, Palu G \& Boscaro M. Prevalence and natural history of adrenal incidentalomas. European Journal of Endocrinology/ European Federation of Endocrine Societies 2003149 273-285. (doi:10.1530/eje.0.1490273)

12 Oishi M, Ueda S, Honjo S, Koshiyama H, Yuba Y \& Takabayashi A. Adrenal cavernous hemangioma with subclinical Cushing's syndrome: report of a case. Surgery Today 201242 973-977. (doi:10.1007/s00595-012-0203-z)

13 Lamas C, López LM, Lozano E, Atienzar M, Ruiz-Mondéjar R, Alfaro JJ \& Botella F. Myelolipomatous adrenal masses causing Cushing's syndrome. Experimental and Clinical Endocrinology \& Diabetes 2009117 440-445. (doi:10.1055/s-0029-1202274)

14 Giordano R, Marinazzo E, Berardelli R, Picu A, Maccario M, Ghigo E \& Arvat E. Long-term morphological, hormonal, and clinical follow-up in a single unit on 118 patients with adrenal incidentalomas. European Journal of Endocrinology/European Federation of Endocrine Societies 2010 162 779-785. (doi:10.1530/EJE-09-0957)

15 Chiodini I. Clinical Review: Diagnosis and treatment of subclinical hypercortisolism. Journal of Clinical Endocrinology and Metabolism 2011 96 1223-1236. (doi:10.1210/jc.2010-2722)

16 Hamrahian AH, Ioachimescu AG, Remer EM, Motta-Ramirez G, Bogabathina H, Levin HS, Reddy S, Gill IS, Siperstein A \& Bravo EL. Clinical utility of noncontrast computed tomography attenuation value (Hounsfield units) to differentiate adrenal adenomas/ hyperplasias from nonadenomas: Cleveland Clinic experience. Journal of Clinical Endocrinology and Metabolism 200590 871-877. (doi:10.1210/jc.2004-1627)
17 Blake MA, Cronin CG \& Boland GW. Adrenal imaging. AJR. American Journal of Roentgenology 2010194 1450-1460. (doi:10.2214/AJR.10.4547)

18 Ramsay JA, Asa SL, van Nostrand AW, Hassaram ST \& de Harven EP. Lipid degeneration in pheochromocytomas mimicking adrenal cortical tumors. American Journal of Surgical Pathology 198711 480-486. (doi:10.1097/00000478-198706000-00009)

19 Blake MA, Krishnamoorthy SK, Boland GW, Sweeney AT, Pitman MB, Harisinghani M, Mueller PR \& Hahn PF. Low-density pheochromocytoma on CT: a mimicker of adrenal adenoma. AJR. American Journal of Roentgenology 2003181 1663-1668. (doi:10.2214/ajr.181.6.1811663)

20 Sane T, Schalin-Jäntti C \& Raade M. Is biochemical screening for pheochromocytoma in adrenal incidentalomas expressing low unenhanced attenuation on computed tomography necessary? Journal of Clinical Endocrinology and Metabolism 201297 2077-2083. (doi:10.1210/jc.2012-1061)

21 Arnaldi G \& Boscaro M. Adrenal incidentaloma. Best Practice \& Research. Clinical Endocrinology \& Metabolism 201226 405-419. (doi:10.1016/ j.beem.2011.12.006)

22 Nieman LK. Approach to the patient with an adrenal incidentaloma. Journal of Clinical Endocrinology and Metabolism 201095 4106-4113. (doi:10.1210/jc.2010-0457)

23 Comlekci A, Yener S, Ertilav S, Secil M, Akinci B, Demir T, Kebapcilar L, Bayraktar F, Yesil S \& Eraslan S. Adrenal incidentaloma, clinical, metabolic, follow-up aspects: single centre experience. Endocrine 2010 37 40-46. (doi:10.1007/s12020-009-9260-5)

24 Terzolo M, Pia A, Alì A, Osella G, Reimondo G, Bovio S, Daffara F, Procopio M, Paccotti P, Borretta G et al. Adrenal incidentaloma: a new cause of the metabolic syndrome? Journal of Clinical Endocrinology and Metabolism 200287 998-1003. (doi:10.1210/jcem.87.3.8277)

25 Tauchmanovà L, Rossi R, Biondi B, Pulcrano M, Nuzzo V, Palmieri EA, Fazio $S$ \& Lombardi G. Patients with subclinical Cushing's syndrome due to adrenal adenoma have increased cardiovascular risk. Journal of Clinical Endocrinology and Metabolism 200287 4872-4878. (doi:10.1210/ jc.2001-011766)

26 Erbil Y, Ademoğlu E, Ozbey N, Barbaros U, Yanik BT, Salmaslioğlu A, Bozbora A \& Ozarmağan S. Evaluation of the cardiovascular risk in patients with subclinical Cushing syndrome before and after surgery. World Journal of Surgery 200630 1665-1671. (doi:10.1007/ s00268-005-0681-x)

27 Bernini G, Moretti A, Iacconi P, Miccoli P, Nami R, Lucani B \& Salvetti A. Anthropometric, haemodynamic, humoral and hormonal evaluation in patients with incidental adrenocortical adenomas before and after surgery. European Journal of Endocrinology/European Federation of Endocrine Societies 2003148 213-219. (doi:10.1530/eje.0.1480213)

28 Toniato A, Merante-Boschin I, Opocher G, Pelizzo MR, Schiavi F \& Ballotta E. Surgical versus conservative management for subclinical Cushing syndrome in adrenal incidentalomas: a prospective randomized study. Annals of Surgery 2009249 388-391. (doi:10.1097/ SLA.0b013e31819a47d2)

29 Morelli V, Reimondo G, Giordano R, Della Casa S, Policola C, Palmieri S, Salcuni AS, Dolci A, Mendola M, Arosio M et al. Long-term follow-up in adrenal incidentalomas: an Italian multicenter study. Journal of Clinical Endocrinology and Metabolism 201499 827-834. (doi:10.1210/jc.2013-3527)

Received 19 February 2015

Revised version received 25 May 2015

Accepted 29 May 2015 